

\title{
A Planar Quad-band Band-Pass Filter Employing Dual-Mode Band-Stop Resonators
}

Yi Wu, Erwan Fourn, Philippe Besnier

\section{To cite this version:}

Yi Wu, Erwan Fourn, Philippe Besnier. A Planar Quad-band Band-Pass Filter Employing DualMode Band-Stop Resonators. International Microwave Filter Workshop 2021, Nov 2021, Perugia, Italy. hal-03435157

\author{
HAL Id: hal-03435157 \\ https://hal.science/hal-03435157
}

Submitted on 18 Nov 2021

HAL is a multi-disciplinary open access archive for the deposit and dissemination of scientific research documents, whether they are published or not. The documents may come from teaching and research institutions in France or abroad, or from public or private research centers.
L'archive ouverte pluridisciplinaire HAL, est destinée au dépôt et à la diffusion de documents scientifiques de niveau recherche, publiés ou non, émanant des établissements d'enseignement et de recherche français ou étrangers, des laboratoires publics ou privés. 


\section{A Planar Quad-band Band-Pass Filter Employing Dual-Mode Band-Stop Resonators}

\author{
$\mathrm{Yi} \mathrm{Wu}$ \\ Univ Rennes, INSA Rennes, IETR, UMR CNRS 6164 \\ Rennes, France \\ wuyiciomp@gmail.com
}

\author{
Philippe Besnier \\ Univ Rennes, INSA Rennes, IETR, UMR CNRS 6164 \\ Rennes, France \\ Philippe.Besnier@insa-rennes.fr
}

\author{
Erwan Fourn \\ Univ Rennes, INSA Rennes, IETR, UMR CNRS 6164 \\ Rennes, France \\ Erwan.Fourn@insa-rennes.fr
}

\begin{abstract}
A compact split-type quad-band band-pass filter employing dual-mode stub-load band-stop resonators is presented in this paper. The basic coupling schematic is originated from frequency transformation methods. Then, a dual-mode band-stop resonator, which can provide two controllable transmission zeros, is employed to replace the two single-mode band-stop resonators to achieve the same response. The filter has been synthesized, designed and simulated in planar microstrip technology to demonstrate the feasibility of the proposal. Comparing with filters based on single-mode resonators. This solution provides a relatively compact footprint, which features an attractive solution for filters' miniaturization.
\end{abstract}

Index Terms-Band-pass filter, dual-mode band-stop resonator, frequency transformation, planar, quad-band.

\section{INTRODUCTION}

Band-pass filters (BPFs) are essential elements for both transmitter and receiver radio frequency front ends. With the rapid advancement of new wireless networking technologies, the study of multiband band-pass filters (MBPFs) has become a hot subject [1]-[3].

In recent decades, several methods have been explored to achieve multiple pass-bands responses. Moreover, to realize a compact footprint, multi-mode resonators based MBPFs are presented using numerous topologies. In [4] and [5], authors use high-temperature superconducting (HTS) stub loaded resonators and multi-mode split ring resonators (SRRs) to design tri-band MBPFs, respectively. Very good insertion losses are observed for the two cases. However, it is not easy for a proposed design approach to achieve the desired central frequency due to difficulties in controlling each mode. In [6], authors propose a series of open stub-loaded shorted stepped-impedance resonator to design MBPFs up to quadbands. Nevertheless, one can hardly place the frequency locations of some modes at the desired frequencies. In [7], a compact quad-band band-pass filter using quad-mode stepped impedance resonator is investigated. Transmission zeros were realized among each pass-band by adding open-loop SIRs at both input/output ports, which results in high isolation and frequency selectivity but generates high losses. In [8], dualmode SIW resonators are used to design MBPFs. However, the method also faces challenges to specify each pass-band locations. Recently, frequency transformation methods have been proposed and used to synthesize and design MBPFs [9], [10] with close pass-bands. Anyway, the non-coupled implementation structures make their minimization difficult.

In this paper, a compact coupled quad-band band-pass filter is proposed. A dual-mode stub-loaded resonators (SLRs) and classical open-end single-mode half wavelength resonator are used to provide three independent and fully controllable transmission zeros. Based on the proposed topology, four pass-bands can be achieved. A compact quad-band filter is optimally synthesized, designed and simulated. The design procedure is simple and leads to the minimization of the overall size of the circuit.

\section{The Topology of the Proposed Dual-mode BASED QUAD-BAND BAND-PASS FILTER}

Fig. 1] shows two topologies that can achieve quad-band filtering responses. Fig. 1(a) represents the coupling topology of a classical quad-band BPF. It is designed by the use of single-mode coupled resonators based on the frequency transformation method [9]. In this figure, the two orange dots represent the band-pass resonators. The other gray dots represent the band-stop resonators (i.e. resonators 3 and 5 create the first transmission zero; resonators 4 and 6 create the second transmission zero; resonators 7 and 8 create the third transmission zero, respectively). In the design process, the resonating frequencies of each resonator and all coupling values can be derived according to the specified bandwidth of each pass-band. However, as we can see from the topology, the central band-pass resonators in the star configuration are highly heavy loaded. At least three band-stop branches are connected to a single band-pass resonator, which may introduce undesired cross-coupling during physical implementation. To cope with this issue, we propose the topology in Fig. 1(b) employing dual-mode band-stop resonators. By comparing the two topologies, we can see that single-mode band-stop resonators 3 and 4,5 and 6 are replaced by the dual-mode resonator $3^{I, I I}$ and $4^{I, I I}$ in Fig. 1(b) This topology 
can avoid the cross-coupling between single-mode band-stop resonators 3 and 4 on the one hand, 5 and 6 om the other hand. Simultaneously, it can further minimize the footprint of the circuit.

The described novel topology can be realized by various techniques. Here we focus on planar implementations. A traditional open-ended half-wavelength microstrip resonator can be used to provide controlled TZs. The classical SLRs [11] will be employed for dual-mode resonators. Typically, the SLR consists in a uniform impedance transmission line and a vertically loaded stub. Because of its symmetry, the resonator may be investigated using even/odd-mode analysis. According to the study in [11], [12], the odd mode of this type of resonator is only influenced by the electrical length of the uniform resonator. Nevertheless, the even mode can be adjusted by both the electrical length of the uniformed resonator and the impedance values of the stub. That is, SLR enables the propagation of two modes, one of them can be controlled independently. Such kind of resonators have been used to design MBPFs [13], [14] or antennas [15]. However, in the applications mentioned above, they are all used as band-pass resonators. Differently, in this study, we use SLRs as band-stop resonators, which can provide two controllable TZs. Since in the new topology, the SLRs are transformed by the immittance inverters $k_{13}^{I}\left(k_{13}^{I I}\right)$ and $k_{24}^{I}\left(k_{24}^{I I}\right)$. Thus, the two reflection zeros created by traditional SLRs will be transformed to two transmission zeros.

Based on the theory in [16], the input $Q_{S}$ and output $Q_{L}$ quality factors in Fig. 11.b) for input and output can be written as:

$$
\begin{aligned}
& Q_{S}=b_{0} g_{0} g_{1} \\
& Q_{L}=b_{0} g_{2} g_{3}
\end{aligned}
$$

$g_{k}(k \in[0 ; 3])$ are the capacitance values in a classical lowpass prototype, that can be chosen according to a specified return loss level. The coupling coefficient between different band-pass resonators can be written as:

$$
k_{1,2}=\frac{m_{1,2}}{b_{0}},
$$

where $m_{1,2}$ denotes the normalized coupling coefficients between the first and second band-pass resonators. It is equal to $m_{1,2}=1 / \sqrt{g_{1} g_{2}}$. The couplings between band-pass resonators and band-stop ones can be expressed as:

$$
k_{j}=\frac{1}{\sqrt{b_{0} b_{j}}}
$$

$b_{0}$ is the slope parameter value of the band-pass filter, $b_{j}$ are the ones of band-stop resonators, $j$ is equal to $3^{I, I I}, 4^{I, I I}$, 7 or 8 .

\section{DESIGN EXAMPLES}

To show the effectiveness of this alternative coupling topology, a second order quad-band filter is presented in this section. The four pass-bands are chosen as follows:

1) Pass-band 1: $3.00 \mathrm{GHz}-3.10 \mathrm{GHz}(\mathrm{BW}: 100 \mathrm{MHz})$;

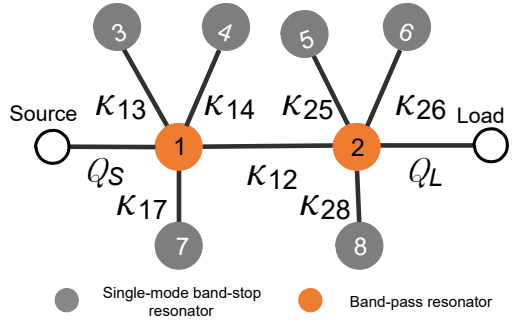

(a)

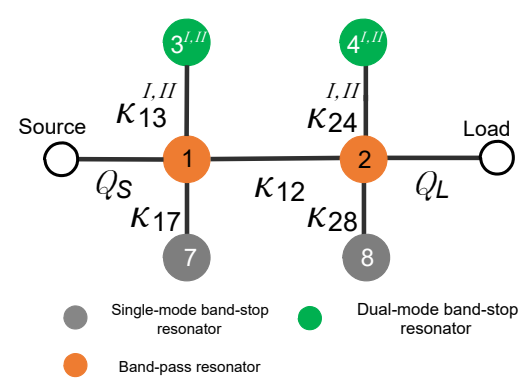

(b)

Fig. 1. Coupling diagram of a quad-band band-pass filter. (a) Quad-band band-pass filter based on single-mode band-pass and band-stop resonators; (b) Quad-band band-pass filter based on single-mode band-pass and mixed single- and dual-mode band-stop resonators.

2) Pass-band 2: $3.20 \mathrm{GHz}-3.30 \mathrm{GHz}(\mathrm{BW}: 100 \mathrm{MHz})$;

3) Pass-band 3: $3.45 \mathrm{GHz}-3.55 \mathrm{GHz}(\mathrm{BW}: 100 \mathrm{MHz})$;

4) Pass-band 4: $3.65 \mathrm{GHz}-3.80 \mathrm{GHz}(\mathrm{BW}: 150 \mathrm{MHz})$.

To reach $-20 \mathrm{~dB}$ ripple level in the pass-band, according to [9], the specifications lead to the following resonant frequencies and design parameters: $f_{1}=f_{2}=3.388 \mathrm{GHz}, f_{3^{I}}=f_{4^{I}}=$ $3.134 \mathrm{GHz}, f_{3^{I I}}=f_{4^{I I}}=3.372 \mathrm{GHz}, f_{7}=f_{8}=3.608 \mathrm{GHz}$. The $Q$ factors and coupling coefficients are $Q_{S}=Q_{L}=5.006$, $k_{1,2}=0.2207 . k_{13}^{I}=k_{24}^{I}=0.07222, k_{13}^{I I}=k_{24}^{I I}=0.0948$. $k_{17}=k_{28}=0.06922$. The theoretical response of this filter is shown in Fig. 2 .

The topology in Fig. 1(b) has been implemented in microstrip technology on Rogers 6010 substrate with $h=1.27$ $\mathrm{mm}$, relative permittivity $\varepsilon_{r}=10.2$ and $\tan \delta=0.0023$, associated with a double-sided copper layer with thickness $18 \mu \mathrm{m}$ and conductivity $5.8 \times 10^{7} \mathrm{~S}_{\mathrm{m}} \mathrm{m}^{-1}$. The layout consists of two resonating cells, each one achieved using a straight uniform open-ended half-wavelength band-pass resonator, a single-mode open-ended U-shaped half-wavelength band-stop resonator, a dual-mode SLR and a feeding line as shown in Fig. 3

Fig. 4 shows the simulated results of the proposed quadband MBPFs based on the association of single-mode resonators and dual-mode resonators. The four passbands are centered at $3.06 \mathrm{GHz}, 3.30 \mathrm{GHz}, 3.50 \mathrm{GHz}$ and $3.73 \mathrm{GHz}$, respectively. The minimum insertion losses of the four passbands are $1.50 \mathrm{~dB}, 1.52 \mathrm{~dB}, 1.48 \mathrm{~dB}$ and $1.02 \mathrm{~dB}$. The return losses are better than $15 \mathrm{~dB}$ for all the pass-bands. A fabricated filter and its associated measurement will be presented during the conference. 


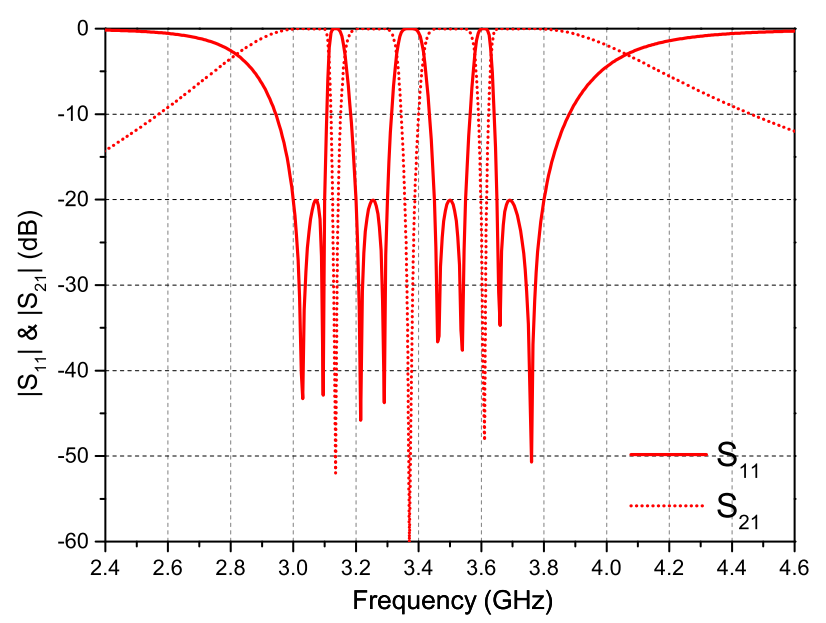

Fig. 2. Theoretical responses of quad-band filter.

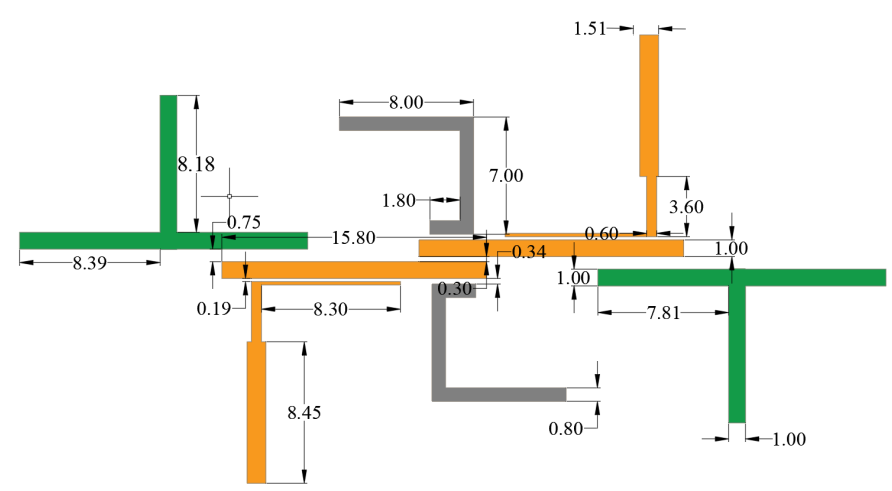

Fig. 3. Layout of the proposed quad-band filter (Units (mm)).

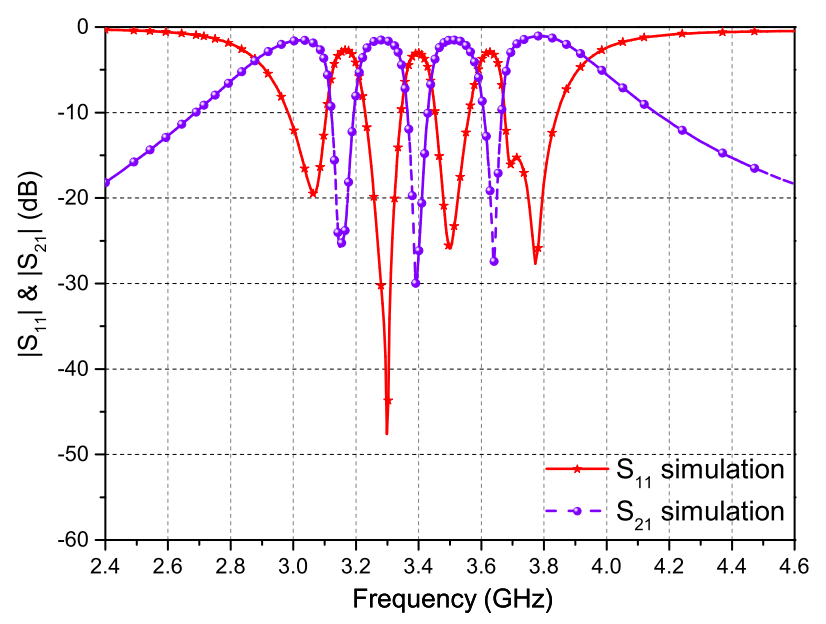

Fig. 4. Simulation responses of quad-band filter.

\section{CONCLUSION}

A compact second-order quad-band filter with arbitrary specified bandwidth has been designed and realized in this paper. The mixed single-mode and dual-mode band-stop resonators have been investigated to minimize the filters' footprint. A good agreement between the theory and EM simulations has validated the proposed design principle and topology.

\section{REFERENCES}

[1] D. J. Simpson, R. Gómez-García, and D. Psychogiou, "Single-/multiband bandpass filters and duplexers with fully reconfigurable transferfunction characteristics," IEEE Trans. Microw. Theory Techn., vol. 67, no. 5, pp. 1854-1869, 2019.

[2] C.-F. Chen, T.-Y. Huang, and R.-B. Wu, "Design of dual-and triplepassband filters using alternately cascaded multiband resonators," IEEE Trans. Microw. Theory Techn., vol. 54, no. 9, pp. 3550-3558, 2006.

[3] C. Quendo, E. Rius, and C. Person, "An original topology of dual-band filter with transmission zeros," in IEEE MTT-S International Microwave Symposium Digest, 2003, vol. 2. IEEE, 2003, pp. 1093-1096.

[4] H. Liu, J. Lei, X. Guan, L. Sun, and Y. He, "Compact triple-band high-temperature superconducting filter using multimode stub-loaded resonator for ism, wimax, and wlan applications," IEEE Trans. Appl. Supercond., vol. 23, no. 6, pp. 99-103, 2013.

[5] H.-W. Liu, Y. Wang, Y.-C. Fan, X.-H. Guan, and Y. He, "Triple-band high-temperature superconducting microstrip filter based on multimode split ring resonator," Appl. Phys. Lett., vol. 103, no. 14, p. 142603, 2013.

[6] J. Xu, W. Wu, and C. Miao, "Compact microstrip dual-/tri-/quad-band bandpass filter using open stubs loaded shorted stepped-impedance resonator," IEEE Trans. Microw. Theory Techn., vol. 61, no. 9, pp. 31873199, 2013.

[7] D. Bukuru, K. Song, F. Zhang, Y. Zhu, and M. Fan, "Compact quadband bandpass filter using quad-mode stepped impedance resonator and multiple coupling circuits," IEEE Trans. Microw. Theory Techn., vol. 65, no. 3, pp. 783-791, 2017.

[8] K. Zhou, C.-X. Zhou, H.-W. Xie, and W. Wu, "Synthesis design of siw multiband bandpass filters based on dual-mode resonances and split-type dual-and triple-band responses," IEEE Trans. Microw. Theory Techn., vol. 67 , no. 1, pp. 151-161, 2018.

[9] Y. Wu, E. Fourn, P. Besnier, and C. Quendo, "Direct synthesis of quadband band-pass filter by frequency transformation methods," in 2019 49th European Microwave Conference (EuMC). IEEE, 2019, pp. 196199.

[10] Y. Wu, E. Fourn, P. Besnier, and C. Quendo, "Direct synthesis of multiband band-pass filters with generalized frequency transformation methods," IEEE Trans. Microw. Theory Techn., vol. 69, no. 8, pp. 38203831, Aug. 2021.

[11] X. Y. Zhang, J.-X. Chen, Q. Xue, and S.-M. Li, "Dual-band bandpass filters using stub-loaded resonators," IEEE Microw. Wireless Compon. Lett., vol. 17, no. 8, pp. 583-585, 2007.

[12] V. Crnojević-Bengin, Advances in multi-band microstrip filters. Cambridge, U.K.: Cambridge Univ. Press, 2015.

[13] X. Lai, C.-H. Liang, H. Di, and B. Wu, "Design of tri-band filter based on stub loaded resonator and dgs resonator," IEEE Microw. Wireless Compon. Lett., vol. 20, no. 5, pp. 265-267, 2010.

[14] X. Y. Zhang, Q. Xue, and B. J. Hu, "Planar tri-band bandpass filter with compact size," IEEE Microw. Wireless Compon. Lett., vol. 20, no. 5, pp. 262-264, 2010

[15] C. X. Mao, S. Gao, Y. Wang, B. Sanz-Izquierdo, Z. Wang, F. Qin, Q. X. Chu, J. Li, G. Wei, and J. Xu, "Dual-band patch antenna with filtering performance and harmonic suppression," IEEE Trans. Antennas and Propag., vol. 64, no. 9, pp. 4074-4077, 2016.

[16] G. L. Matthaei, L. Young, and E. M. T. Jones, Microwave filters, impedance-matching networks, and coupling structures. Dedham, MA, USA: Artech House, 1980. 